\title{
Faktor-Faktor Yang Mempengaruhi Pengetahuan Ibu Gavida I Tentang Inisiasi Menyusu Dini (IMD) Di Puskesmas Sa'dan Kab. Toraja Utara Tahun 2018
}

\author{
Factors Affecting Knowledge of Ms. Gavida I About Early Breastfeeding Initiation (IMD) \\ at Sa'dan Puskesmas in North Toraja Regency in 2018
}

\author{
Sumarce Bongga \\ Akademi Kebidanan Sinar Kasih Toraja \\ Email : sumarcebonggaakbidsinarkasih@gmail.com
}

\begin{abstract}
Abstrak
Inisiasi menyusu dini adalah segera meletakan bayi di dada ibu (ada kontak kulit ibu dan kulit bayinya sekurang-kurangnya 1 jam untuk memberikan kesempatan kepada bayi menyusu segera mungkin). Tujuan penelitian ini untuk mengetahui faktor-faktor apakah yang mempegaruhi pengetahuan ibu gravida 1 tentang Inisiasi menyusui dini di Puskesmas Sa'dan Kab. Toraja utara tahun 2018. Jenis penelitian ini adalah yang bersifat deskriptif, jumlah Sampel 25 0rang. Hasil penelitian menunjukan ibu pengetahuan baik tidak sekolah 1 (4\%), pendidikan dasar $8(32 \%)$, pendidikan menengah $9(36 \%)$, dan perguruan tinggi $2(8 \%)$. pengetahuan cukup tidak sekolah $1(4 \%)$, pendidikan dasar $1(4 \%)$, pendidikan menengah $2(8 \%)$. Sedangkan pengetahuan kurang tidak sekolah 1 (4). Ibu dengan pengetahuan baik mendapat informasi melalui media cetak 4 (16\%), media elektronik 6 (24\%), penyuluhan $5(20 \%)$ pengetahuan cukup mendapat informasi melalui media cetak $4(16 \%)$, media elektronik 1 (4\%), dan yang dari penyuluhan 4 (16\%), sedangkan pengetahuan kurang mendapat informasi melalui penyuluhan 1 (4\%). Ibu dengan pengetahuan baik bekerja $2(8 \%)$, dan tidak bekerja $14(56 \%)$ ibu pengetahuan cukup tidak bekerja 8 (32\%), sedangkan ibu pengetahuan kurang tidak bekerja $1(4 \%)$. Serta Ibu dengan pengetahuan baik umur $<20$ tahun $3(12 \%)$, dan umur 20-35 tahun $13(52 \%)$, sedangkan pengetahuan cukup umur $<20$ tahun 4 (16\%), dan umur 20-35 tahun $5(20 \%)$, sedangkan pengetahuan kurang umur $<20$ tahun 1 (4\%). Berdasarkan hasil penelitian faktor-faktor yang mempengaruhi pengetahuan ibu gavida I tentang Inisiasi Menyusu Dini (IMD) adalah pendidikan dengan besar responden berada pada tingkat pengetahuan menegah (52\%), sumber informasi tentang IMD paling banyak dari media elektronik (40\%), Pekerjaan responden tidak bekerja (IRT) sebanyak $(92 \%)$, dan umur dengar rata-rata umur 20-30 tahun paling banyak adalah 18 orang (72\%). Pada petugas kesehatan lebih aktif dengan kegiatan sosialisai dan edukasi IMD kepada masyarakat perluh lebih ditingkatkan lagi dengan melibatkan peran serta tenaga kesehatan
\end{abstract}

Kata Kunci: Faktor, Inisiasi menyusui dini (IMD), ibu dan bayi

\begin{abstract}
Early breastfeeding initiation is to immediately put the baby in the mother's chest (there is maternal skin contact and the skin of the baby at least 1 hour to give the baby an opportunity to suckle as soon as possible). The purpose of this study was to determine what factors affected the knowledge of gravidian mothers about early breastfeeding initiation in the Sa'dan health center, district. North Toraja in 2018. This type of research is descriptive. With samples of 25 people. The results showed that mothers of knowledge were either not in school 1 (4\%), basic education $8(32 \%)$, secondary education 9 (36\%), and tertiary education 2 (8\%). insufficient knowledge of school 1 (4\%), basic education 1 (4\%), secondary education 2 (8\%). While knowledge is not less school 1 (4). Mothers with good knowledge get information through print media 4 (16\%), electronic media 6 (24\%), counseling $5(20 \%)$ knowledge enough to get information through print media $4(16 \%)$, electronic media $1(4 \%)$, and those from counseling $4(16 \%)$, while knowledge is poorly informed through counseling $1(4 \%)$. Mothers with good knowledge of working 2 (8\%), and not working 14 (56\%) mothers of knowledge are not enough to work 8 (32\%), while mothers of knowledge do not work 1 (4\%). As well as mothers with knowledge of good age $<20$ years 3 (12\%), and ages 20-35 years 13 (52\%), while knowledge is sufficiently aged $<20$ years $4(16 \%)$, and ages $20-35$ years $5(20 \%)$, while knowledge is less than $<20$ years old 1 (4\%). Based on the results of the research, the factors that influence the knowledge of Gavida I mothers regarding Early Breastfeeding Initiation (IMD) are education with a large number of respondents at the middle level of knowledge (52\%), the largest source of information about IMD from electronic media (40\%) not working (IRT) as much as (92\%), and the age of hearing the average age of 20-30 years is 18 people (72\%). Health workers who are more active with IMD socialization and education activities for the community need to be further enhanced by involving the participation of health workers
\end{abstract}

Keywords: Factors, Initiation of early breastfeeding (IMD), mother and baby 


\section{PENDAHULUAN}

Inisiasi menyusu dini adalah segera meletakan bayi di dada ibu (ada kontak kulit ibu dan kulit bayinya sekurangkurangnya 1 jam untuk memberikan kesempatan kepada bayi menyusu segera mungkin)[1]. Inisiasi menyusui dini merangsang keluanya ASI, memberi kekebalan pada bayi serta meningkatkan kekuatan batin antara ibu dan bayinya. IMD mencegah pendarpahan pada ibu.

Menurut data WHO 2010 sekitar 22\% bayi meninggal di bawah umur 28 hari, dan sekitar 40\% dari kematian tersebut bisa diselamatkan dengan pemberian ASI. Artinya Inisiasi Menyusui dini bisa mengurangi Angka Kematian Balita sampai 88\%[2]. Riset Kesehatan Dasar 2013 menyebutkan bahwa bayi di Indonesia yang mendapat ASI eksklusif hingga umur 6 bulan baru 15,3\%. Inisiasi menyusui dini kurang dari satu jam setelah bayi lahir adalah 9,3\%, tertinggi di Nusa Tenggara Timur 56,2\% dan terendah di Maluku 13,0\% [3]. Sebagian besar proses mulai menyusui dilakukan pada kisaran waktu 1-6 jam setelah bayi lahir tetapi masih ada 11,1\% proses mulai disusui dilakukan setelah 48 jam. Pemberian kolostrum cukup baik, dilakukan oleh 74,7\% ibu kepada bayinya. Jumlah bayi yang diberi ASI eksklusif di Sulawesi Selatan tahun 2011 yaitu 57,48\% dan tahun 2010 57,05\% [4], sedangkan di kota Toraja Utara, prevalensi ASI eksklusif sampai 6 bulan rata-rata perbulan tahun 2016 yaitu 62,68\% dan prevalensi IMD 27,2\% [4]

Berbagai upaya dalam mengurangi angka kematian bayi terutama di bawah 28 hari salah satunya adalah untuk meningkatkan kesadaran dan pengetahuan tentang pentingnya pemberian ASI pada bayi baru lahir, untuk mengatasi masalah tersebut, pemerintah membuat program-program yang dapat mendukung penggunaan ASI antara lain melalui pemberian pendidikan kesehatan tentang pentingnya pemberian ASI pada masyarakat [5]

Berdasarkan data diatas pengetahuan sangat penting bagi ibu gravida 1 tentang Inisiasi Menyusui Dini dalam paya mengurangi angka kematian bayi. Oleh karena itu, sangat penting dilakukan penelitian mengenai faktor-faktor yang mempengaruhi pengetahuan pada ibu gravida 1 tentang Inisiasi Menyusui Dini di puskesmas sa'dan dalam rangkan upaya peningkatan angka kehidupan pada bayi baru lahir di lokasi tersebut. .

\section{METODE}

Jenis penelitian ini adalah yang bersifat deskriptif yaitu penelitian yang dilakukan untuk menggambarkan bagaimana pengetahuan ibu gravida I tentang Inisiasi Menyusui Dini. Penelitian ini dilakukan di Puskesmas Sa'dan kab. Toraja utara tahun 2018 Populasi dalam penelitian ini adalah seluruh ibu hamil di Puskesamas Sa,dan pada bulan januari -april sebanyak 78 orang. Sampel adalah bagian dari jumlah populasi yang dijadikan responden yang menjadi sampel dalam penelitian ini adalah ibu gravida I yang melakukan kunjugan di Puskesmas Sa'dan pada bulan januari-april tahun 2018 sebanyak 25 0rang

\section{HASIL}

1. Pengetahuan Ibu Gravid I Berdasarkan Tingkat Pendidikan

Tabel 1. Gambaran distribusi frekuensi pengetahuan ibu gravida I tentang Inisiasi Menyusu Dini berdasarkan pendidikan di Puskesmas Sa'dan Kab. Toraja Utara Tahun 2018

\begin{tabular}{|c|c|c|c|c|c|c|c|c|c|c|}
\hline \multirow{3}{*}{ Variabel } & \multicolumn{8}{|c|}{ Pendidikan } & \multirow{2}{*}{\multicolumn{2}{|c|}{ Total }} \\
\hline & \multicolumn{2}{|c|}{ Tidak Sekolah } & \multicolumn{2}{|c|}{ Dasar } & \multicolumn{2}{|c|}{ Menengah } & \multicolumn{2}{|c|}{$\begin{array}{c}\text { Perguruan } \\
\text { Tinggi }\end{array}$} & & \\
\hline & $\mathbf{n}$ & $\%$ & $\mathbf{n}$ & $\%$ & $\mathbf{n}$ & $\%$ & $\mathbf{n}$ & $\%$ & $\mathbf{n}$ & $\%$ \\
\hline \multicolumn{11}{|l|}{ Tingkat pendidikan } \\
\hline Baik & 1 & 4 & 8 & 32 & 9 & 36 & 2 & 8 & 20 & 80 \\
\hline Cukup & 1 & 4 & 1 & 4 & 2 & 8 & 0 & 0 & 4 & 16 \\
\hline Kurang & 1 & 0 & 0 & 0 & 0 & 0 & 0 & 0 & 1 & 4 \\
\hline Total & 3 & 8 & 9 & 36 & 11 & 44 & 2 & 8 & 25 & 100 \\
\hline
\end{tabular}


Berdasarkan tabel 1 di dapatkan 25 responden yang berpengetahuan baik dengan tidak sekolah 1 orang (4\%), pendidikan dasar 8 orang (32\%), pendidikan menengah 9 orang (36\%), dan perguruan tinggi 2 orang (8\%) sedangkan yang berpengetahuan cukup dengan tidak sekolah ada 1 orang (4\%), pendidikan dasar ada 1 orang (4\%), pendidikan menengah ada 2 orang (8\%). Sedangkan yang berpengetahuan kurang dengan tidak sekolah ada 1 orang (4).

2. Pengetahuan Ibu Gravid I Berdasarkan Sumber Informasi

Tabel 2. Gambaran distribusi frekuensi pengetahuan ibu gravida I tentang Inisiasi Menyusu Dini berdasarkan sumber informasi di Puskesmas Sa'dan Kab. Toraja UtaraTahun 2018

\begin{tabular}{|c|c|c|c|c|c|c|c|c|c|}
\hline \multirow{3}{*}{ Variabel } & \multicolumn{7}{|c|}{ Sumber Informasi } & \multirow{2}{*}{\multicolumn{2}{|c|}{ Total }} \\
\hline & \multicolumn{3}{|c|}{ Media Cetak } & \multicolumn{2}{|c|}{ Media } & \multicolumn{2}{|c|}{ Penyuluhan } & & \\
\hline & & $\mathbf{n}$ & $\%$ & $\mathbf{n}$ & $\%$ & $\mathbf{n}$ & $\%$ & $\mathbf{n}$ & $\%$ \\
\hline \multicolumn{10}{|l|}{ Tingkat pendidikan } \\
\hline Baik & 4 & & 16 & 6 & 24 & 5 & 20 & 15 & 60 \\
\hline Cukup & 4 & & 16 & 1 & 4 & 4 & 16 & 9 & 36 \\
\hline Kurang & 0 & & 0 & 0 & 0 & 1 & 4 & 1 & 4 \\
\hline Total & 8 & & 32 & 7 & 28 & 10 & 40 & 25 & 100 \\
\hline
\end{tabular}

Sumber : Data Primer, 2018

Berdasarkan tabel 2 di dapatkan 25 responden yang berpengetahuan baik yang mendapat sumber informasi melalui media cetak ada 4 orang (16\%), media elektronik ada 6 orang (24\%), dari penyuluhan ada 5 orang (20\%) sedangkan yang berpengetahuan cukup yang mendapat informasi dari media cetak ada 4 orang (16\%), media elektronik ada 1 orang (4\%), dan yang dari penyuluhan ada 4 rorang (16\%), sedangkan yang berpengetahuan kurang yang mendapat informasi dari penyuluhan ada 1 orang (4\%).

3. Pengetahuan Ibu Gravid I Berdasarkan pekerjaan

Tabel 3. Gambaran distribusi frekuensi pengetahuan ibu gravida I tentang Inisiasi Menyusu Dini berdasakan pekerjaan di Puskesmas Sa'dan Kab. Toraja UtaraTahun 2018

\begin{tabular}{|c|c|c|c|c|c|c|}
\hline \multirow{3}{*}{ Variabel } & \multicolumn{4}{|c|}{ Pekerjaan } & \multirow{2}{*}{\multicolumn{2}{|c|}{ Total }} \\
\hline & \multicolumn{2}{|c|}{ Bekerja } & \multicolumn{2}{|c|}{ Tidak Bekerja } & & \\
\hline & $\mathbf{n}$ & $\%$ & $\mathbf{n}$ & $\%$ & $\mathbf{n}$ & $\%$ \\
\hline \multicolumn{7}{|l|}{ Tingkat Pengetahuan } \\
\hline Baik & 2 & 8 & 14 & 56 & 16 & 64 \\
\hline Cukup & 0 & 0 & 8 & 32 & 8 & 32 \\
\hline Kurang & 0 & 0 & 1 & 4 & 1 & 4 \\
\hline Total & 2 & 8 & 23 & 92 & 25 & 100 \\
\hline
\end{tabular}

Sumber : Data Primer, 2018

Berdasarkan tabel 3 didapatkan 25 responden yang berpengetahuan baik yang bekerja ada 2 orang (8\%), dan tidak bekerja ada 14 orang (56\%) sedangkan ibu yang berpengetahuan cukup yang tidak bekerja ada 8 orang (32\%), sedangkan ibu yang berpengetahuan kurang yang tidak bekerja ada 1 orang (4\%). 
4. Pengetahuan Ibu Gravid I Berdasarkan umur

Tabel 4. Gambaran distribusi frekuensi pengetahuan ibu gravida I tentang Inisiasi Menyusu Dini berdasakan umur di Puskesmas Sa'dan Kab. Toraja UtaraTahun 2018

\begin{tabular}{|c|c|c|c|c|c|c|c|c|}
\hline \multirow{3}{*}{ Variabel } & \multicolumn{6}{|c|}{ Umur } & \multirow{2}{*}{\multicolumn{2}{|c|}{ Total }} \\
\hline & \multicolumn{2}{|c|}{$<20$ Tahun } & \multicolumn{2}{|c|}{ 20-35 Tahun } & \multicolumn{2}{|c|}{ > 35 Tahun } & & \\
\hline & $\mathbf{n}$ & $\%$ & $\mathbf{n}$ & $\%$ & $\mathbf{n}$ & $\%$ & $\mathbf{n}$ & $\%$ \\
\hline \multicolumn{9}{|l|}{ Tingkat pendidikan } \\
\hline Baik & 3 & 12 & 13 & 52 & 0 & 0 & 16 & 64 \\
\hline Cukup & 3 & 12 & 5 & 20 & 0 & 0 & 8 & 32 \\
\hline Kurang & 1 & 4 & 0 & 0 & 0 & 0 & 1 & 4 \\
\hline Total & 7 & 28 & 18 & 72 & 0 & 0 & 25 & 100 \\
\hline
\end{tabular}

Sumber : Data Primer, 2018

Berdasarkan tabel 4 di dapat responden 25 orang yang berpengetahuan baik dengan umur $<20$ tahun ada 3 orang (12\%), dan umur 20-35 tahun ada 13 orang (52\%), sedangkan ibu yang berpengetahuan cukup dengan umur $<20$ tahun ada 4 orang (16\%), dan umur 20-35 tahun ada 5 orang (20\%), sedangkan ibu yang berpengetahuan kurang dengan umur $<20$ tahun ada 1 oang (4\%)

\section{PEMBAHASAN}

1. Pengetahuan Ibu Gravid I Berdasarkan Tingkat Pendidikan

Menurut Notoatmodjo pengetahuan adalah merupakan hasil dari "tahu" dan ini terjadi setelah orang melakukan penginderaan terhadap suatu objek tertentu. Penginderaan terjadi melalui panca indra manusia. Sebagian besar pengetahuan manusia diperoleh dari mata dan telinga[6].

Pendidikan berarti bimbingan yang diberikan seseorang kepada orang lain agar dapat memahami suatu hal. Semakin tinggi pendidikan seseorang,semakin mudah pula mereka menerima informasi, dan pada akhirnya pengetahuan yang dimilikinya akan semakin banyak. Sebaliknya, jika seseorang memiliki tingkat pendidikan yang rendah, maka akan menghambat perkembangan sikap peran tersebut terhadap penerimaan informasi dan nilai-nilai yang baru diperkenalkan. Salah satu fakto yang mempegaruhi pengetahuan seseorang adalah pendidikan. Pendidikan mempunyai peranan penting dalam menentukan kualitas hidup seseorang. Semakin banyak ilmu yang di peroleh maka semakin luas pula wawasannya. Sama halnya dengan penelitian ini, kebanyakan yang bepengetahuan baik adalah mereka yang berpendidikan tinggi. Pendidikan akan memudahkan seseorang meneima masukan atau pendapat maupun pemahaman tentang sesuatu seperti hal dengan IMD. Tidak bisah kita samakan orang yang bependidikan tinggi tentunya akan lebih mudah memahami tentang pentingnya melakukan IMD. Tingkat pendidikan ibu yang endah mengakibatkan kurangnya pengetahuan ibu dalam melaksanakan IMD. Pengetahuan ini diperoleh baik secara fomal maupun informasi. Sedangkan ibu yang mempunyai tingkat pendidikan yang lebih tinggi, umumnya terbuka meneima perubahan atau hal-hal guna pemelihaaan kesehatannya. Pendidikan juga akan membuat seseorang terdoong untuk ingin tahu mencarai pengalaman sehingga informasi yang diterima akan menjadi pengetahuan.

Jadi penelitian ini sejalan dengan teori bab II yang mengatakan semakin tinggi pendidikan seseorang maka semkain baik pula pengetahuannya.

2. Pengetahuan Ibu Gravid I Berdasarkan Sumber Informasi

Informasi adalah pesan (ucapan atau ekspresi) atau kumpulan pesan yang diterima dari order sekuens dari 
simbol, atau makna yang dapat sitafsirkan dari pesan atau kumpulan pesan. Informasi dapat direkan atau ditrasmisikan. Hal ini dapat dicacat sebagai tanda-tanda, atau sebagai sinyal berdasarkan gelombang. Informasi adalah jenis acara yang mempengaruhi suatu negara dari sistem dinamis. Para konsep memiliki banyak arti lain dalam konteks yang berbeda. Informasi bisa dikatakan sebagai pengetahuan yang didapat dari pembelajaran, pengalaman, atau instruksi [7].

Seperti dikatakan peran media sangat penting untuk mendapat informasi dengan demikian pengetahuan akan bertambah dengan demikian pengetahuan akan bertambah, dalam penelitian ini lebih banyak ibu yang mendapatkan informasi melalui media elektronik yaitu televisi dan smartphone.

Seperti yang kita ketahui TV dan smartphone merupakan media elektronik yang sekarang perannya sangat penting, sudah jarang orang tidak memiliki smartphone dengan begitu mereka dengan mudahnya mengakses melalui internet atau melihatnya di TV tentang IMD. Peran media terutama Audio visual sudah memang tidak di ragukan lagi, semakin mudahnya orang mendapatkan pengetahuan dimanapun kita berada.

Dan dalam penelitian ini lebih banyak ibu dengan dengan cukup mendapatkan sumber informasi melalui media elektronik yaitu TV dan internet, begitupun ibu yang berpengetahuan baik mereka juga mendapatkan pengetahuan yang sama melalui media sumber infomasi yaitu TV dan HP. Jadi dapat di simpulkan bahwa sumber infomasi sangat mempengaruhi pengetahuan tentang IMD. Upaya merubah pengetahuan ibu tersebut dibutuhkan banyak upaya, salah satunya melalui pendidikan kesehatah.

3. Pengetahuan Ibu Gravid I Berdasarkan pekerjaan

Pekerjaan dalam arti luas adalah aktivitas utama yang dilakukan oleh manusia. Dalam arti sempit, istilah pekejaan digunkan untuk suatu tugas atau kerja yang menghasilkan uang bagi seseorang.

Salah satu faktor yang mempengaruhi pengetahuan adalah pekerjaan. Ibu bekerja adalah wanita dinamis yang mempunyai kelebihan dan kemampuan untuk mengimbangi berbagai tenggung jawab (misalnya menjadi ibu, istri dan guru) dengan membeikan tumpuan tanggung jawab dengan cara yang tersendiri. Sedangkan ibu tidak bekerja adalah ibu yang hanya menjalankan fungsinya sebagai ibu rumah tangga dan banyak menghabiskan waktunya dirumah tanpa terikat pekerjaan diluar rumah berbeda ibu yang bekerja dengan yang tidak bekerja akan memperoleh informasi yang berbeda dengan masalah IMD.

Namun dalam penelitian ini lebih banyak ibu yang tidak bekerja mendapatkan pengetahuan lebih tinggi dibanding ibu yang bekerja mungkin disebabkan karena ibu yang bekerja lebih mementingkan pekerjaan, namun hal itu tidak dapat menjadi pegangan ibu yang tidak bekerja akan mengetahui banyak tentang IMD.

4. Pengetahuan Ibu Gravid I Berdasarkan umur

Usia atau umur individu yang terhitung mulai saat dilahirkan sampai berulang tahun. Semakin cukup umur, tingkat kematangan dan kekuatan seseorang akan lebih matang dalam berfikir.

Jadi penelitian ini sejalan dengan teori yang mengatakan umur mempengaruhi terhadap daya tangkap dan pola pikir seseorang. Semakin bertambah usia akan semakin berkembang pula daya tangkap dan pola pikirnya, sehingga pengetahuan yang diperolehnya semakin membaik.

\section{KESIMPULAN DAN SARAN}

Berdasarkan hasil penelitian faktor-faktor yang mempengaruhi pengetahuan ibu gavida I tentang Inisiasi Menyusu Dini (IMD) adalah pendidikan dengan besar responden berada pada tingkat pengetahuan menegah (52\%), sumber informasi tentang IMD paling banyak dari media elektronik (40\%), Pekerjaan responden tidak bekerja (IRT) sebanyak (92\%), dan umur dengar rata-rata umur 20-30 tahun paling banyak adalah 18 orang (72\%). 
Pada petugas kesehatan lebih aktif dengan kegiatan sosialisai dan edukasi IMD kepada masyarakat perluh lebih ditingkatkan lagi dengan melibatkan peran serta tenaga kesehatan.

\section{DAFTAR PUSTAKA}

[1] Y. Aprillia, "Analisis Sosialisasi Program Inisiasi Menyusu Dini Dan Asi Eksklusif Kepada Bidan Di Kabupaten Klaten." Universitas Diponegoro, 2010.

[2] R. Juliastuti, "Hubungan Tingkat Pengetahuan, Status Pekerjaan Ibu, dan Pelaksanaan Inisiasi Menyusu Dini dengan Pemberian ASI Eksklusif." Universitas Sebelas Maret, 2011.

[3] K. Kesehatan and K. K. RI, "Riset kesehatan dasar," Jakarta Badan Penelit. dan Pengemb. Kesehat. Dep. Kesehat. Republik Indones., 2013.

[4] D. K. P. Sul-Sel, "Profil Kesehatan Provinsi Sulawesi Selatan Tahun 2012," Profil Kesehat. Provinsi Sulawesi Selatan, 2012.

[5] I. A. C. Manuaba, "Memahami Kesehatan reproduksi wanita ed 2," 2009.

[6] S. Notoatmodjo, Pengantar Pendidikan Kesehatan dan Ilmu Perilaku Kesehatan. Yogyakarta: Andi of Set, 2003.

[7] "PENGGUNAAN MEDIA AUDIO VISUAL," pp. 1-19. 